\title{
Oculomotor Nerve Neoplasm
}

National Cancer Institute

\section{Source}

National Cancer Institute. Oculomotor Nerve Neoplasm. NCI Thesaurus. Code C6994.

A neoplasm involving the oculomotor nerve. 